\title{
Evaluation of Larval Development of Dirofilaria immitis in Different Populations of Aedes aegypti and Aedes albopictus
}

\author{
Gílcia Aparecida de Carvalho ${ }^{1 *}$, Rafael Trindade Maia ${ }^{2}$, Rafael Antonio Nascimento Ramos ${ }^{3,4}$, \\ Carlos Fernando Salgueirosa de Andrade ${ }^{5}$, Maria Aparecida da Gloria Faustino ${ }^{3}$, \\ Leucio Câmara Alves ${ }^{3}$ \\ ${ }^{1}$ Unidade Acadêmica de Garanhuns, Universidade Federal Rural de Pernambuco, Garanhuns, Brazil \\ ${ }^{2}$ Centro de Desenvolvimento Sustentável do Semiárido-Unidade Acadêmica de Educação do Campo, \\ Universidade Federal de Campina Grande, Sumé, Brazil \\ ${ }^{3}$ Departamento de Medicina Veterinária, Universidade Federal Rural de Pernambuco, Recife, Brazil \\ ${ }^{4}$ Dipartimento di Medicina Veterinaria, Università degli Studi di Bari, Valenzano, Italy \\ ${ }^{5}$ Universidade Estadual de Campinas, Campinas, Brazil \\ Email: "gilciasilva@yahoo.com.br
}

Received June 27, 2013; revised July 27, 2013; accepted August 17, 2013

Copyright (C 2013 Gílcia Aparecida de Carvalho et al. This is an open access article distributed under the Creative Commons Attribution License, which permits unrestricted use, distribution, and reproduction in any medium, provided the original work is properly cited.

\begin{abstract}
Dirofilaria immitis is an important nematode parasite commonly known as heartworm. This filarioid is transmitted by culicid vectors and primarily affects dogs, but other animals may also become infected, such as wild carnivores, cats and humans. The aim of the present study was to assess the development of $D$. immitis larvae in different culicid populations under laboratory conditions. Adult females of populations of Aedes aegypti from the city of Recife (P1), the city of Campinas (P2) and the Rockefeller strain from the Centers for Disease Control (P3) and one population of Aedes albopictus from Recife (P4) were fed for two hours with infected dog blood containing 2,000 microfilariae/ml of $D$. immitis. After artificial feeding, the specimens were maintained under controlled conditions. Ten females from each population were dissected daily over 14 days. The infection ratio and vector efficiency index were calculated and $D$. immitis development from $\mathrm{L}_{1}$ to $\mathrm{L}_{3}$ was assessed. The larvae in P1, P2, P3 and P4 reached the third stage in 11, 10, 14 and 9 days, respectively. The vector efficiency index was 53.8\%, 20.0\%, 7.4\% and 25.2\% in P1, P2, P3 and P4, respectively. The findings demonstrate that $D$. immitis larvae develop in all culicid populations studied herein. Based on mosquito mortality, development time and VEI the A. albopictus population from Recife (P4) demonstrated the best performance as vector. This is the second report of $D$. immitis development in A. albopictus from Brazil. The present data reinforce the role of this species as vector of $D$. immitis in an area where greater importance has long been given to $A$. aegypti.
\end{abstract}

Keywords: Culicid; Vector; Heartworm; Dog; Experimental Infection

\section{Introduction}

Dirofilariasis is an important parasitic disease caused by the nematode Dirofilaria immitis, also known as heartworm [1]. This filarioid primarily affects dogs, but infection has also been reported in cats [2,3], wild carnivores $[4,5]$ and humans [6]. In this later host, infection is characterized by the presence of pulmonary nodules (the so-called "coin lesion") and no apparent symptoms [7].

Transmission occurs through mosquito vectors, which

*Corresponding author. are the most important vectors that belong to the genera Culex, Aedes and Anopheles [8,9]. Briefly, first stage larvae $\left(\mathrm{L}_{1}\right)$ are taken up by blood-sucking female mosquitoes and develop through to the infective final larvae stage $\left(L_{3}\right)$ in approximately 14 days [10]. The vector competence of a culicid population is the primary factor for $D$. immitis transmission in an endemic area. However, characteristics such as the immune reaction, environmental conditions (e.g., temperature and humidity) and genetic traits among $D$. immitis populations may be factors which affect the vector capacity of culicids [11]. 
In Brazil, studies on D. immitis vectors are scarce. In the southeastern region of the country, Aedes scapularis and Aedes taeniorhynchus have been shown to be the main vectors, while Culex quinquefasciatus seems to have secondary importance [2]. Also in this region (state of Rio de Janeiro), an experimental study demonstrated Aedes aegypti as a potential vector of $D$. immitis [12]. In the northeastern region $C x$. quinquefasciatus and $A$. taeniorhynchus have been found naturally infected [13], but little is known regarding the epidemiological importance of these species, especially the latter. Unfortunately, the vector competence of two species well established throughout Brazil (A. aegypti and A. albopictus), has been poorly studied.

Therefore, the aim of the present study was to assess the development of $D$. immitis larvae in three populations of $A$. aegypti and one of $A$. albopictus from different geographic areas under laboratory conditions.

\section{Material and Methods}

\subsection{D. immitis Microfilariae}

Blood containing microfilariae was obtained from a dog positive for $D$. immitis in the microscopic analysis (see below). The dog was a three-year-old male that lived in the metropolitan region of Recife $\left(7^{\circ} 45^{\prime} 0^{\prime \prime} S\right.$ and $\left.34^{\circ} 51^{\prime} 0^{\prime \prime} \mathrm{W}\right)$, state of the Pernambuco, Brazil.

\subsection{Microscopic Diagnosis (Modified Knott Test)}

The microscopic analysis was performed using the modified Knott test [14]. Briefly, 1 ml EDTA blood was mixed with $9 \mathrm{ml}$ of distilled water and centrifuged for 5 $\min$ at $300 \times \mathrm{g}$. The supernatant was discarded, leaving 1 $\mathrm{ml}$ of solution to which two drops of methylene blue solution were added. The sediment was transferred to glass slides, covered with coverslip and examined under a light microscope at different magnifications. All filarioid larvae found were morphologically identified as D. immitis.

\subsection{Mosquito Populations and Experimental Infection}

Four different mosquito populations were used: $A$. aegypti from the city of Recife, Brazil (P1), A. aegypti from the city of Campinas, Brazil (P2), A. aegypti Rockfeller strain from the Centers for Disease Control in the USA (P3) and A. albopictus from Recife (P4).

A total of 4,800 female mosquitoes (3,600 for the test populations and 1,200 for the control) aged from three to seven days were used [15]. The artificial blood meal was performed as previously described [10]. The test mosquitoes were fed for two hours with the infected blood, which was previously assessed as containing 2,000 microfilariae/ml. Non-infected blood was offered to the control group. After feeding, the mosquitoes were maintained under controlled temperature $\left(28^{\circ} \mathrm{C} \pm 2^{\circ} \mathrm{C}\right)$ and relative humidity $(>70 \%)$.

\subsection{Mosquito Dissection and Microscopic Examination}

For the detection of $D$. immitis larvae and developmental stages, ten mosquitoes from each population were dissected daily. On Day 14, all remaining living mosquitoes were also dissected. The mosquitoes were fixed on slides containing a drop of $0.9 \%$ physiological saline solution, dissected with a sterile scalpel and immediately examined under a light microscope (Olympus BX41 TF) at different magnifications. All stages of $D$. immitis larvae were morphologically identified [16].

\subsection{Data Analysis}

The infection ratio (IR) [17] and vector efficiency index (VEI) were calculated [18]. Linear regression was used to determine the influence of the ingestion of $D$. immitis microfilariae on mosquito mortality. Analysis of variance was used to compare larval development up to the infectious stage in the female mosquitoes as well as mortality in the different populations. The BioStat program (version 2.0) was employed for the statistical analysis [19].

\section{Results}

After feeding, the mosquitoes exhibited a similar rate of engorgement: 97.6\%, 91.5\%, 97.6\% and 93.3\% in P1, P2, P3 and P4, respectively, and $96.6 \%$ in the control group. Table 1 displays the mean ingestion of microfilariae in each population. Microfilaria ingestion was statistically similar among P1, P3 and P4 (P > 0.05), whereas P2 ingested a significantly smaller number of microfilariae ( $\mathrm{P}$ $<0.01)$.

Throughout the study period, mosquito mortality was greater in P1 than P2, P3 and P4 (P<0.01). However, this higher mortality rate was not influenced by the number of microfilariae ingested $(\mathrm{F}=0.6899$; $\mathrm{P}>0.05)$. Two peaks in mosquito mortality were found in all populations, one on the second day post-infection and one after the detection of $L_{3}$. At the end of the study, overall mortality in the control group was $3.4 \%$.

The infection rate among the populations ranged from $11.6 \%$ to $17.5 \%$ (Table 2 ). This parameter was not influenced by the proportion of engorged females $(\mathrm{F}=$ 12.8754; $\mathrm{P}>0.05)$, but was affected by the number of microfilariae ingested $(\mathrm{F}=141.3808 ; \mathrm{P}<0.01)$.

D. immitis larval development from $\mathrm{L}_{1}$ to $\mathrm{L}_{3}$ occurred in all infected populations. In $\mathrm{P} 1, \mathrm{~L}_{1}$ was found on Day 3 post-infection, $\mathrm{L}_{2}$ on Day 7 and a low number of $\mathrm{L}_{3}(\mathrm{n}=$ 7) were retrieved on Day 11. In P2 and P3, $L_{1}$ on Day 6 post-infection, $L_{2}$ was found on Day 8 and $L_{3}$ was found 
Table 1. Mean number of microfilariae ingested, rate of recovery of $L_{3}$ and VEI in mosquito females of different populations (A. aegypti Recife-P1, A. aegypti CampinasP2, A. aegypti lineage Rockfeller-P3 and A. albopictusP4). Specimens were fed with dog blood containing 2,000 microfilaria/ml of $D$. immitis.

\begin{tabular}{cccc}
\hline Pop. & Mean of $\mathrm{L}_{1}$ ingested $\pm \mathrm{SD}^{*}$ & Mean of $\mathrm{L}_{3} \pm \mathrm{SD}^{* *}$ & VEI (\%) \\
\hline P1 & $13 \pm 10.4^{\mathrm{a}}$ & $7.0 \pm 0^{\mathrm{B}}$ & 53.8 \\
P2 & $5 \pm 4^{\mathrm{b}}$ & $1 \pm 0^{\mathrm{A}}$ & 20 \\
P3 & $13.4 \pm 7.7^{\mathrm{a}}$ & $1 \pm 0^{\mathrm{A}}$ & 7.4 \\
P4 & $11.3 \pm 9.4^{\mathrm{a}}$ & $2.8 \pm 2^{\mathrm{C}}$ & 25.2 \\
\hline
\end{tabular}

"Mean number of microfilariae ingested after blood meal; ${ }^{* *}$ Mean number of $\left(\mathrm{L}_{3}\right)$ recovery 14 days post-infection; different letters in the same column indicate statistical difference.

Table 2. Total number of dissected and infected mosquito females of different populations (A. aegypti Recife-P1, $A$. aegypti Campinas-P2, A. aegypti lineage Rockfeller-P3 and A. albopictus-P4). Specimens were fed with dog blood containing 2,000 microfilaria/ml of $D$. immitis.

\begin{tabular}{ccc}
\hline Pop. & Dissected females & Infected females n (\%) \\
\hline P1 & 849 & $149(17.5 \%)$ \\
P2 & 821 & $95(11.5 \%)$ \\
P3 & 878 & $149(16.9 \%)$ \\
P4 & 838 & $131(15.6 \%)$ \\
\hline
\end{tabular}

on Days 10 and 14, respectively. Melanized larvae and few larvae remaining as $L_{1}$ were detected at the end of the study in all populations. $D$. immitis larvae exhibited a comparatively short development time when infecting $A$. albopictus (P4), with larvae reaching $\mathrm{L}_{1}, \mathrm{~L}_{2}$ and $\mathrm{L}_{3}$ at Days 2, 5 and 9, respectively.

The number of $\mathrm{L}_{3}$ obtained 14 days post-infection (Table 1) was not influenced by the number of microfilariae ingested $(\mathrm{F}=0.0415 ; \mathrm{P}>0.05)$. The VEI ranged from $7.4 \%$ to $53.8 \%$ in the different populations (Table $\mathbf{1}$ ).

\section{Discussion}

The present study provides evidence that $D$. immitis larvae can develop efficiently in all culicid populations studied herein. Based on mortality, development time and VEI the A. albopictus population (P4) demonstrated the best performance as vector of this nematode.

The mean ingestion of microfilariae was similar among P1, P3 and P4, whereas P2 ingested a significantly smaller number. From a biological standpoint, microfilaria ingestion is an important limiting factor related to the vector competence of a mosquito population. However, the mechanisms that impair the ingestion of $D$. immitis microfilariae and lead to mosquito infection re- main unclear. It has been shown that some mosquito populations have efficient defense mechanisms against species of Dirofilaria soon after ingestion [20]. Probably, when microfilariae reach the Malpighian tubule, intracellular development is blocked by defense mechanisms activated by the host, resulting in larval death and lysis [20].

A greater mortality rate was found among the mosquitoes in P1. Interestingly, this parameter was not influenced by the number of microfilariae ingested ( $F=$ 0.6899; $\mathrm{P}>0.05$ ). Both mortality peaks occurred during critical post-infection times: first during the penetration of $\mathrm{L}_{1}$ into the Malpighian tubule cells (between Days 1 and 2 post-infection) and soon after the detection of $\mathrm{L}_{3}$. In both events, Malpighian tubule cells were destroyed, with the magnitude of the destruction depending on the quantity of larvae, causing death in P1. As previous states [21] an efficient mosquito vector should survive independently of the number of ingested microfilariae thus, P1 may exhibit a comparatively low degree of vector competence.

D. immitis development was observed in all populations studied herein, with the maximum VEI (53.8\%) found for A. aegypti from Recife (P1). However, this population may not be considered an efficient vector due to the high mortality rate observed (70.7\%). The minimal differences in development time found among the populations of A. aegypti were expected, since the same nematode strain was used for all populations. Previous studies have been reported different development times for this filarioid when different strains of nematode and mosquitoes are used [16,22].

Among the four populations studied, one merits particular attention, A. albopictus from Recife (P4) exhibited low mortality and a considerable VEI (25.2\%). Furthermore, larvae reached the third infective stage in only nine days. A. albopictus is reported to be the primary potential vector of $D$. immitis in Italy [23]. The importance of this mosquito as a vector for $D$. immitis in Brazil has been assessed in a single study [12]. Nonetheless, its vector capacity has interesting epidemiological implications. A. albopictus is considered a secondary vector of human arboviruses due to its preferential feeding on animals rather than humans, unlike the highly anthropophilic behavior of A. aegypti [24]. Based on feeding preference $A$. albopictus may have a major veterinary importance for $D$. immitis transmission among animals, which should be studied better. It is important stress that the A. albopictus population evaluated herein proved to be susceptible to infection and allowed $D$. immitis larvae development. However, further studies evaluating the vector capacity of other populations of this species in different regions of Brazil should be carried out. 


\section{Conclusion}

In conclusion, $D$. immitis larvae developed in all mosquito populations studied. Based on factors as mortality, development time and VEI, the A. albopictus population from Recife demonstrated the best performance as vector. This study is the second description of the development of D. immitis in A. albopictus in Brazil. Moreover, the findings suggest that this culicid species may perform an important role as a vector for $D$. immitis in an area (i.e., Brazil) where greater importance has long been attributed to A. aegypti. Field studies should be carried out to clarify the real importance of this culicid species in the transmission of D. immitis in Brazil.

\section{REFERENCES}

[1] J. W. McCall, C. Genchi, L. H. Kramer, J. Guerrero and L. Venco, "Heartworm Disease in Animals and Humans," Advances in Parasitology, Vol. 66, No. 1, 2008, pp. 193285. http://dx.doi.org/10.1016/S0065-308X(08)00204-2

[2] N. Labarthe, M. L. Serrão, Y. F. Melo, S. J. Oliveira and R. Lourenço-de-Oliveira, "Potential Vectors of Dirofilaria immitis (Leidy, 1856) in Itacoatiara, Oceanic Region of Niterói Municipality, State of Rio de Janeiro, Brazil,” Memórias do Instituto Oswaldo Cruz, Vol. 93, No. 4, 1998, pp. 425-432.

http://dx.doi.org/10.1590/S0074-02761998000400001

[3] F. C. L. Maia, J. W. McCall, Vol. A. Silva, C. A. Peixoto, P. Supakorndej, N. Supakorndej and L. C. Alves, "Structural and Ultrastructural Changes in the Lungs of Cats Felis catus (Linnaeus, 1758) Experimentally Infected with D. immitis (Leidy, 1856)," Veterinary Parasitology, Vol. 176, No.4, 2011, pp. 304-312. http://dx.doi.org/10.1016/j.vetpar.2011.01.014

[4] T. A. Nelson, D. G. Gregory and J. R. Laursen, "Canine Heartworms in Coyotes in Illinois," Journal of Wildlife Diseases, Vol. 39, No. 3, 2003, pp. 593-599.

[5] K. L. Paras, S. E. Little, M. Vol. Reichard and M. H. Reiskind, "Detection of Dirofilaria immitis and Ehrlichia Species in Coyotes (Canis latrans), from Rural Oklahoma and Texas,” Vector Borne Zoonotic Diseases, Vol. 12, No. 7, 2012, pp. 619-621. http://dx.doi.org/10.1089/vbz.2011.0815

[6] S. Pampioglione and F. Rivasi, "Human Dirofilariasis Due to Dirofilaria (Nochtiella) repens: An Update of World Literature from 1995 to 2000,” Parassitologia, Vol. 42, No. 3-4, 2000, pp. 231-254.

[7] R. Rodrigues-Silva, H. Moura, G. Dreyer and L. Rey, "Human Pulmonary Dirofilariasis: A Review," Revista do Instituto de Medicina Tropical de São Paulo, Vol. 37, No. 6, 1995, pp. 523-530. http://dx.doi.org/10.1590/S0036-46651995000600009

[8] K. W. Ludlam, L. A. Jachowski and G. F. Otto, "Potential VECTORS of Dirofilaria immitis," Journal of American Mosquito Control Association, Vol. 157, No. 1, 1970, pp. 1354-1359.

[9] G. Cancrini, P. Scaramozzino, S. Gabrielli, M. Di Paolo,
L. Toma and R. Romi, "Aedes albopictus and Culex pipiens Implicated as Natural Vectors of Dirofilaria repens in Central Italy,” Journal of Medical Entomology, Vol. 44, No. 6, 2007, pp. 1064-1066.

http://dx.doi.org/10.1603/0022-2585(2007)44[1064:AAA CPI]2.0.CO;2

[10] G. A. Carvalho, L. C. Alves, R. T. Maia, C. F. S. Andrade, R. A. N. Ramos and M. A. G. Faustino, "Vector Competence of Culex quinquefasciatus Say, 1823 Exposed to Different Densities of Microfilariae of Dirofilaria immitis (Leidy, 1856),” Revista Brasileira de Entomologia, Vol. 52, No. 4, 2008, pp. 658-662. http://dx.doi.org/10.1590/S0085-56262008000400018

[11] B. M. Christensen, "Laboratory Studies on the Development and Transmission of Dirofilaria immitis by Aedes trivittatus,” Mosquito News, Vol. 37, No. 3, 1977, pp. 367372.

[12] M. L. C. Serrão, “Competência Vetorial de Aedes albopictus (Skuse, 1848) Proveniente do Estado do Rio de Janeiro, Brasil, para Dirofilaria immitis (Leidy, 1856) Railliet \& Henry, 1911,” Ph.D. Dissertation, Universidade Federal Rural do Rio de Janeiro, Rio de Janeiro, 2004.

[13] S. M. M. Ahid and R. Lourenço-de-Oliveira, "Mosquitos Vetores Potenciais de Dirofilariose Canina na Região Nordeste do Brasil,” Revista de Saúde Pública, Vol. 33, No. 6, 1999, pp. 560-565. http://dx.doi.org/10.1590/S0034-89101999000600007

[14] W. L. Newton and W. H. Wright, "The Occurrence of a Dog Filarid Other Than Dirofilaria immitis in the United States,” Journal of Parasitology, Vol. 42, No. 3, 1956, pp. 246-258. http://dx.doi.org/10.2307/3274849

[15] L. C. Rutledge, R. A. Ward and D. J. Gould, "Studies on the Feeding Response of Mosquitoes to Nutritive Solutions in a New Membrane Feeder," Mosquito News, Vol. 24, No. 4, 1964, pp. 407-419.

[16] A. E. R. Taylor, "The Development of Dirofilaria immitis the mosquito Aedes aegypti," Journal of Helminthology, Vol. 34, No. 1-2, 1960, pp. 27-38. http://dx.doi.org/10.1017/S0022149X00020307

[17] S. M. Ahid, P. S. Vasconcelos and R. Lourenço-de-Oliviera, "Vector Competence of Culex quinquefasciatus Say from Different Regions of Brazil to Dirofilaria immitis," Memórias do Instituto Oswaldo Cruz, Vol. 95, No. 6, 2000, pp. 769-775.

[18] L. Kartman, "Suggestions Concerning an Index Experimental Filarial Infection in Mosquitoes," American Journal Tropical Medicine and Hygiene, Vol. 3, No. 1, 1954, pp. 329-337.

[19] M. Ayres, M. Ayres Jr, D. L. Ayres and A. L. Santos, "BioEstat 2.0: Aplicações Estatísticas nas Áreas das Ciências Biológicas e Médicas,” Sociedade Civil MamirauáCNPq, Brasília, 2000.

[20] M. Vegni-Talluri and G. Cancrini, “An Ultrastructural Study on the Early Cellular Response to Dirofilaria immitis (Nematoda) in the Malpighian Tubules of Aedes aegypti (Refractory Strains),” Parasite, Vol. 1, No. 4, 1994, pp. 343-348.

[21] G. A. Scoles and J. R. Craig, "Variation in Susceptibility 
to Dirofilaria immitis among US Strains of Aedes albopictus," Vector Control Bulletin North Carolina States, Vol. 2, No. 1, 1993, pp. 98-103.

[22] I. L. Mendonça, L. C. Alves, J. W. McCall, M. A. G. Faustino and P. Supakonderj, "Porcentual de Infecção por Dirofilaria immitis (Leidy, 1856) em Aedes aegypti (Linnaeus) Através da Utilização de Membrana Artificial,” Ciência Veterinária nos Trópicos, Vol. 1, No. 1, 1998, pp. 30-32.
[23] G. Cancrini, A. F. Regalbono, I. Ricci, C. Tessarin, S. Gabrielli and M. Pietrobelli, "Aedes albopictus Is a Natural Vector of Dirofilaria immitis in Italy," Veterinary Parasitology, Vol. 118, No. 3-4, 2003, pp. 195-202. http://dx.doi.org/10.1016/j.vetpar.2003.10.011

[24] A. H. Hawley, "The Biology of Aedes albopictus," Journal of American Mosquito Control Association, Vol. 4, No. 2, 1988, p. e39. 